\title{
Gold and Silver Nanoparticles: Synthesis Methods, Characterization Routes and Applications towards Drugs
}

Khalid Alaqad and Tawfik A Saleh*

Department of Chemistry, King Fahd University of Petroleum and Minerals, Dhahran, Saudi Arabia

\begin{abstract}
Nanoparticles are widely used in the biotechnology and biomedical field. Their large surface area, remarkable physical properties, enhanced permeability, and retention effect make them as promising candidates in biomedical applications such as diagnosis and therapy. The gold and silver nanoparticles proved to be the safest for drug applications. The gold and silver nanoparticles are considered very important and interesting for several applications. This review provides a summary of $\mathrm{Au}$ and $\mathrm{Ag}$ nanoparticles synthesis, characterization, and applications. The review will focus on the use of nanoparticles in drug delivery and in determining and sensing of drugs in pharmaceuticals.
\end{abstract}

Keywords: Synthesis; Gold nanoparticles; Silver nanoparticles; Applications

\section{Introduction}

The nano is a Greek word, which means small in size. It is used as the prefix for the billionth from the range 9 to 10. Particles which have two or more dimensions in the size range as 1 to $100 \mathrm{NM}$ are defined as nanoparticles (ASTM International) [1]. Nanoparticles have unique chemical and physical properties as compared to their solid bulk materials because of their high surface area and electronic properties. Furthermore, these particles have been utilized in many applications, for example, electrochemistry, photochemical, and biomedicine [2]. Nanoparticles have many functional platforms that can be utilized for imaging and therapeutic functions. These platforms can be prepared from various inorganic and organic materials, but the inorganic platforms are very important for simultaneous therapy and diagnosis because of their easy modification, high drug loading capacity and stability [3]. Nanoparticles can be used in drug delivery and in the determination of drugs in pharmaceuticals [4].

Gold nanoparticles are widely used in biotechnology and biomedical field because of their large surface area, and high electron conductivity [5]. The modification of the nanometers is conducted to enhance the interaction of these nanoparticles with biological cells [6]. Enhanced permeability and retention are the unique property of nanoparticles to accumulate and interact with the tumor cells. Drug delivery systems depend on nanoparticles, which is used in targeting malignant brain tumors where the conventional therapy is not as much effective [7]. The gold nanoparticles proved to be the safest and much less toxic agents for drug delivery [8]. Nanoparticles such as dendrimers, quantum dots, polymer gels, and gold nanoparticles have more properties and widely used in some application such as drug delivery systems and imaging [9]. Inorganic nanoparticles are widely used as a contrast agent in some application, especially molecular imaging such as computed tomography, positron emission tomography, magnetic resonance imaging, optical imaging, and ultrasound [10].

Gold nanoparticles are synthesized via different techniques [11]. One of the methods to synthesize Au/NPs is laser ablation by Ref. [12]. In addition, there are some applications of gold nanoparticles in electrochemistry involving the determination of Pharmaceutical compounds. It is commonly used in the electrochemical methods because of its ease of fabrication, better sensitivity determination and modification surface. AuNPs are proper for some surface immobilization, acting as conducting materials and enhancing the electron transfer between the surface of gold nanoparticles and the target analyte. Many procedures had been constructed to develop the immune sensor by using modified carbon paste electrode with gold nanoparticles [13]. Colloidal gold, produced by different methods, is used in the medical application. Faraday discovered the formation of gold, which has a deep red color as a liquid solution by chloroaurate reduction $\left(\mathrm{AuCl}_{4}^{-}\right)$with phosphorus in water mixture. Gold nanoparticles have many applications, such as catalysis, optical molecular sensing, cancer therapeutics, and construction blocks in nanotechnology [14].

The applicability of gold nanoparticles in drug delivery systems [15] is due to have some of the properties to make it good vehicle property for drug delivery. Fabrication of gold nanoparticles can perform to have a different size from $1 \mathrm{~nm}$ to $150 \mathrm{~nm}$ [16]. Their structural design enables the coating of the surfaces with various targeting agents. In addition, the important properties are non-toxic and biocompatible [17].

The gold nanoparticles have good physical, chemical and optical properties are presented in Ref. [18]. The individual physical, chemical, and photo properties of gold nanoparticles can be innovative ways to control the transport pharmaceutical compounds and control [19].

The colloidal gold is prepared by citrate reduction method $[15,16,20]$. Synthetic gold nanoparticles of different structure [21] involving gold nanorods [22-24], silica - gold nanoshells [25] and hollow gold NPs [26]. Noble metal nanoparticles distinguish from other nanoplatforms like semiconductor quantum dots, magnetic nanoparticles and polymeric nanoparticle by their single surface plasmon resonance (SPR), which has a small particle size, enhances all the radiative and irradiative properties of the nanoparticles [27].

The silver nanoparticle has many applications due to the large degree of commercialization. Silver $(\mathrm{Ag})$ is an attractive material for

*Corresponding author: Tawfik A Saleh, Department of Chemistry, King Fahd University of Petroleum and Minerals, Dhahran 31261, Saudi Arabia, Tel: +966138601734; E-mail: tawfik@kfupm.edu.sa (or) tawfikas@hotmail.com

Received May 27, 2016; Accepted July 11, 2016; Published July 18, 2016

Citation: Alaqad K, Saleh TA (2016) Gold and Silver Nanoparticles: Synthesis Methods, Characterization Routes and Applications towards Drugs. J Environ Anal Toxicol 6: 384. doi:10.4172/2161-0525.1000384

Copyright: $\odot 2016$ Alaqad K, et al. This is an open-access article distributed under the terms of the Creative Commons Attribution License, which permits unrestricted use, distribution, and reproduction in any medium, provided the original author and source are credited. 
its distinctive properties, such as good conductivity, chemical stability, catalytic activity, and antimicrobial activity [28]. Ag nanoparticles are used in antimicrobial applications since the antimicrobial effect of $\mathrm{Ag}$ ions is well known [29].

Ag NP applications include the medical field as well as in water and air filtration [30]. Furthermore, silver nanoparticles have individual plasmon optical spectra properties which allow being silver nanoparticles used in biosensing application. Table 1 summarizes some advantages and disadvantages of silver and gold nanoparticles.

The most important use of $\mathrm{Ag} / \mathrm{NPs}$ includes the treatment of diseases or targeting of cells, such as interacting with the HIV-1 virus and preventing its ability to bind host cells in vitro [31]. Hybrid materials of Ag nanoparticles with amphiphilic hyperbranched macromolecules are synthesized for use in surface coatings because of its antibacterial activity [32]. The surfaces coated with Ag nanoparticles embedded paint based on vegetable oil showed excellent antimicrobial properties [33]. The water-related diseases like diarrhea and dehydration can be reduced by improving the microbial quality of the drinking water. The bactericidal activity can be reduced by the use of the Ag deposited carbon filters [34]. Bio-aerosols are the airborne particles which cause chronic diseases and developed in the ventilating, heating and airconditioning system in a humid atmosphere. The use of the Ag-coated activated carbon filter effectively removes bio-aerosols [35]. There are several commercial products for wound treatment that contain $\mathrm{Ag}$ as an antimicrobial agent. Nano-crystalline $\mathrm{Ag}$ in wound dressings is used to treat ulcers, and Ag sulfadiazine is used in pastes or creams for treating burn wounds [36].

Gold and silver nanoparticles have been commonly used in different pharmacy applications and drug delivery systems due to their inert nature, stability, high disparity, non-cytotoxicity, and biocompatibility. This review highlights the synthesis and applications of gold and silver nanoparticles in the field of pharmacy and drug delivery.

\section{Properties of Gold and Silver Nanoparticles}

\section{Gold nanoparticles}

The gold nanoparticles properties are the wine-red solution. The interactions of gold nanoparticles play an important role in their properties [37-39]. There are different sizes of gold nanoparticles start from $1 \mathrm{~nm}$ to $8 \mu \mathrm{M}$, and various shapes; for example, spherical ring, sub-octahedral, icosahedral tetrahedral, decahedral, octahedral, and nanorods (Figure 1).

Gold nanoparticles have been commonly utilized in the radiation medicine field as a radiant enhancer [40] and improvement in the therapy of radiation because the ability in drug delivery. Furthermore, $\mathrm{Au} / \mathrm{NPs}$ have different uses or applications in nanotechnology as a platform for labeling of proteins and biomolecular detection.

The Au/NPs are non-toxic particles with large surface area and can be modified with other molecules, and used in biomedical fields [41]. The significance of $\mathrm{Au} / \mathrm{NPs}$ in biochemistry field is due to the compatibility, and optical properties. Nanoparticles are good therapeutic agents due to their ease transport in the diseased cell and carrier-loading drug [42].

Gold nanorods are widely used in the vivo cell imaging because of resonance absorption plasmon and scatter of light in IR [43]. In addition, colloidal Au/NPs have the very small size to introduce in the tissues and cells of biological molecules such as proteins and DNA [44]. Because of their electronic properties, Au/NPs have been commonly utilized in analytical methods and used as an electrode sensor of different samples [6].

\section{Silver nanoparticles}

The potential of Ag/NPs has been widely utilized in nanomedicine, drug delivery, cosmetics, electronic application, and environmental

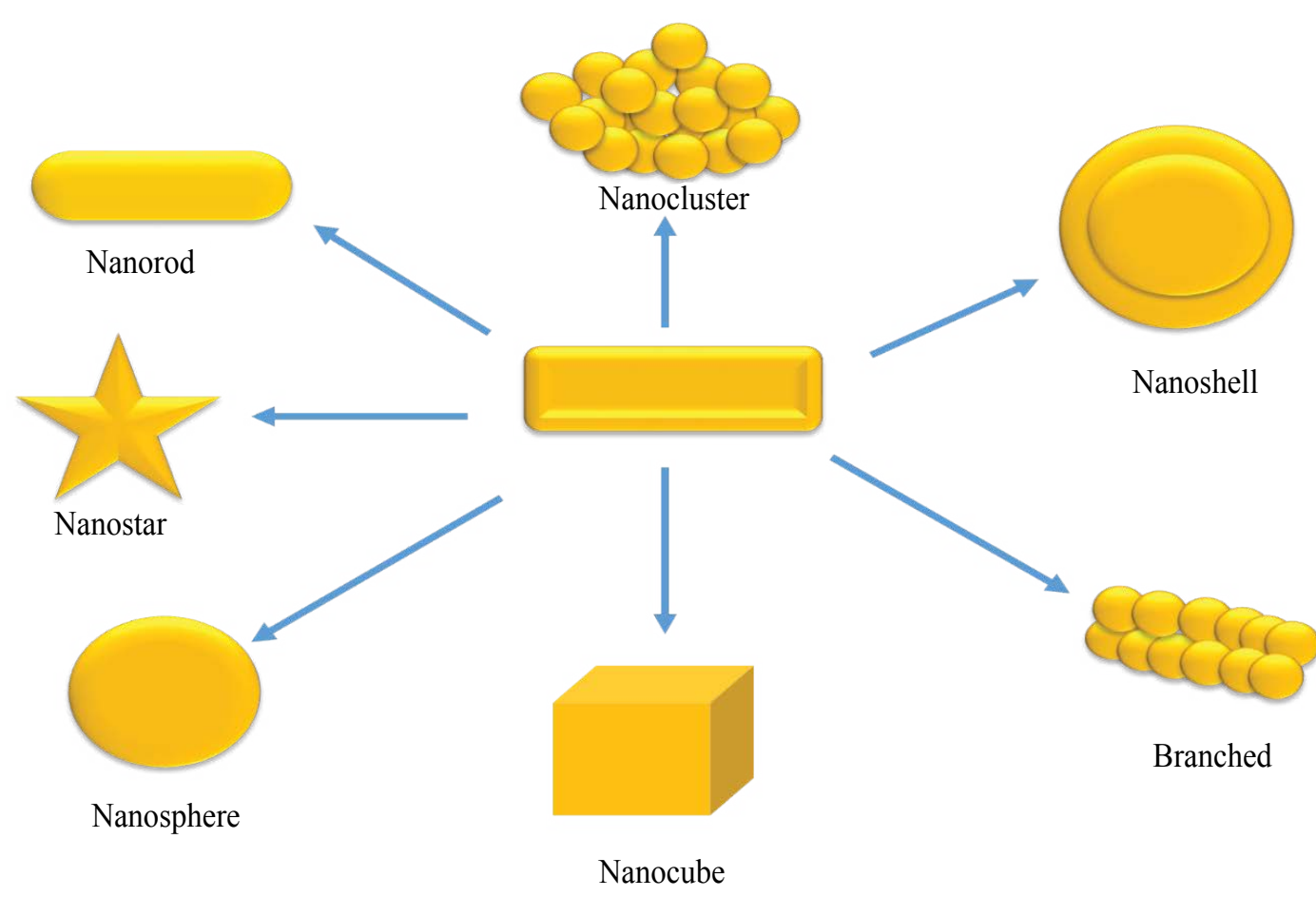

Figure 1: Various shapes of gold nanoparticles. 
protection [45]. Silver nanoparticles own novel biological, chemical, and physical characteristics as compared to their solid silver bulk form [46]. Ag/NPs have special chemical and physical properties, such as surface enhanced Raman scattering and optical behavior, electrical conductivity, high thermal, chemical stability, nonlinear, and catalytic activity [47]. These properties of Ag-NPs obtained in electronics, and for medical application [48]. Ag/NPs are commonly used in the antimicrobial field to treatment microbes such as fungi, virus, and bacteria [49]. Due to their proven antimicrobial properties, $\mathrm{Ag} / \mathrm{NPs}$ are widely used in the daily used commercial products; $\mathrm{Ag} / \mathrm{NPs}$ are used in different applications, such as colloidal coating, and in paints, or in a solid material such as polymer scaffolds. In addition, $\mathrm{Ag} / \mathrm{NPs}$ used in textile industry, where $\mathrm{Ag} / \mathrm{NPs}$ are utilized in the filtration membranes of water due to the slow release rate of the membrane to be utilized as a protective bulkhead against different bacteria and other microbes present in the water [50].

\section{Synthesis of Gold and Silver Nanoparticles}

Different methods have been used to synthesize gold and silver nanoparticles [51]. The techniques used for the preparation of nanoparticles involved biological, physical, and chemical methods (Figure 2).

\section{Chemical methods}

Gold nanoparticles: Chemical technique was suggested by Gimenez et al. to prepare $\mathrm{Au} / \mathrm{NPs}$ by the reduction process of the $\mathrm{HAuCl}_{4}$ through a solution of thiolated chitosan [52]. The method of thermal citrate reduction used in the preparation of Au/NPs via Raman spectroscopy (SERS) by using inositol hexakisphosphate (IP6) to reduce $\mathrm{HAuCl}_{4}$ [53]. In addition, the preparation of $\mathrm{Au} / \mathrm{NPs}$ is by the trisodium citrate, and hydrogen tetrachlorocuprate (III) tetrahydrate (chloroauric acid) [54].

$\mathrm{Au} / \mathrm{NPs}$ can be grown in encapsulated immersed in polyethylene glycol dendrimers and reduced by formaldehyde under near infra-red [55]. Gold nanoparticles are prepared by utilizing peptide-biphenyl hybrids (PBHs) as a stabilizer for gold, and in this method the size range 1.8 to $3.7 \mathrm{~nm}$ was reported [56]. The dendrimers/Au nanoparticles can be prepared by the reduction of a solution of $\mathrm{HAuCl}_{4}$ and sodium borohydride [57]. The synthesis $\mathrm{Au} / \mathrm{NPs}$ with size less than $10 \mathrm{~nm}$ can be by two various thiols involved ethylene glycol and dodecanethiol [58].

Silver nanoparticle preparation: The chemical methods are important to synthesize of Ag-NPs because of the simplicity of preparation in aqueous solution [59]. Monodisperse silver nanocubes were prepared by polyol process, by using a polyvinylpyrrolidone (PVP) polymer with $\mathrm{Ag}\left(\mathrm{NO}_{3}\right)$ in the presence of ethylene glycol as reducing agent [60]. Furthermore, the shape and size of the nanotubes were based on the molar ratio of $\mathrm{Ag}\left(\mathrm{NO}_{3}\right)$ and PVP. In this method, the particle size of $\mathrm{Ag} / \mathrm{NPs}$ with $20 \mathrm{~nm}$ was prepared [61]. On the other hand, monodispersed Ag-NPs were prepared by using $\mathrm{Ag} \mathrm{NO}_{3}$, oleylamine, and liquid paraffin. Oleylamine-paraffin was utilized to control temperature and liquid paraffin was utilized in avoiding the solvents [62]. The preparation of Ag-NPs by the chemical method is based on three factors (a) stabilizing agent (b) reducing agents, and (c) Ag precursor. However, the synthesis process and shape of Ag-NPs depend on the Ag nucleus with various sizes and monodispersity which can be obtained by controlling the nucleation of Ag. This is based on factors like a precursor, $\mathrm{pH}$, temperature, and reducing agents. $\mathrm{Ag} /$ NPs can be synthesized by utilizing $\mathrm{Ag} \mathrm{NO}_{3}$ as a precursor; and sodium borohydride and trisodium citrate as reducing and stabilizing agents.

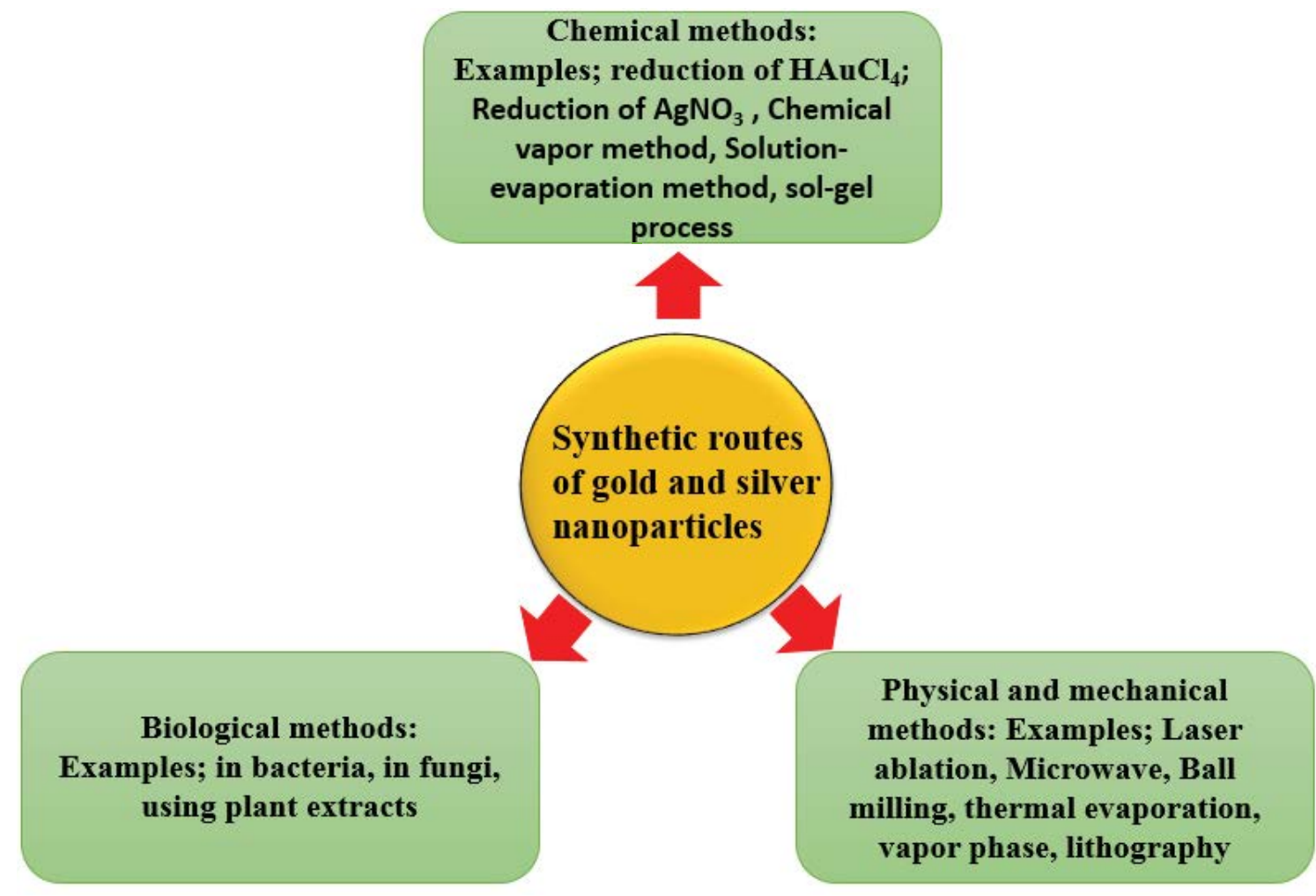

Figure 2: Different methods for synthesis of nanoparticles. 


\begin{tabular}{|l|l|}
\hline $\begin{array}{l}\text { Advantages of silver and gold } \\
\text { Nanoparticles }\end{array}$ & Disadvantages of Nanoparticles \\
\hline $\begin{array}{l}\text { 1 Possibility of high scale production. } \\
2 \text { Long stability [39]. }\end{array}$ & \\
3 Controlled of active drug can be & 1 Less drug loading capacity. \\
achieved. & 2 Dispersion included the amount of \\
4 Avoided of Organic solvents. & water. \\
5 Lyophilized [40]. & 3 The less capacity to load hydrophilic \\
6 Freeze dried to form a powder & drugs. \\
formulation. & \\
\hline
\end{tabular}

Table 1: Some advantages and disadvantages of silver and gold nanoparticles.

The particle size of Ag/NPs was recorded in the range from $5 \mathrm{~nm}$ to 100 $\mathrm{nm}$ and was controlled by optimizing the experimental parameters [63].

The chemical reduction approach was common for the synthesis of $\mathrm{Ag} / \mathrm{NPs}$ by using organic and inorganic reducing agents. Also, various reducing agents, for example, sodium citrate, ascorbate, sodium borohydride $\left(\mathrm{NaBH}_{4}\right), \mathrm{N}, \mathrm{N}$ - dimethylformamide (DMF) and poly(ethylene glycol)- block copolymers elemental hydrogen, polyol process, and Tollens reagent is utilized for reducing $\mathrm{Ag}^{+}$in nonaqueous or aqueous solutions. Silver ions are reduced by reducing agents to form silver $\left(\mathrm{Ag}^{0}\right)$. These clusters lead to the formation of colloidal silver particles [64].

\section{Physical methods}

Gold nanoparticles preparation: The $\gamma$-irradiation technique is one approach for the synthesis of Au/NPs with uniform size from the range 5-40 $\mathrm{nm}$ and high purity, using polysaccharide alginate as stabilizer [65]. The technique of microwave irradiation was used to prepare $\mathrm{Au} /$ NPs by reducing agents such as citric acid and a binding agent such as cetyltrimethylammonium bromide (CTAB) [66]. Furthermore, $\mathrm{Au} / \mathrm{NPs}$ are prepared by using heat or photochemical reduction, and reduction of $\mathrm{HAuCl}_{4}$ by citrate, tartrate, and malate [66]. A common method of photochemical reduction has been recorded for the synthesis of gold-polyethylene glycol nanoparticles by polymerization reactions with size $10-50 \mathrm{~nm}$. Furthermore, in this approach, gold salt is reduced by radical formation coated with polyethylene glycol diacrylate by UV-reaction [67]. One of another method, synthesis porous Au/NPs from alloys of gold is by using $\mathrm{HAuCl}_{4}$ and $\mathrm{AgNO}_{3}$ as precursors, then reduction by $\mathrm{NaBH}_{4}$ as a reducing agent. After that, de-alloying can be achieved by nitric acid [68].

Silver nanoparticle preparation: Different physical methods, such as condensation and evaporation processes are performed for the synthesis of $\mathrm{Ag} / \mathrm{NPs}$. These techniques have their own advantages and disadvantages. One of the demerits of this technique is timeconsuming and need high energy. However, researchers have reported different physical methods for the preparation of Ag/NPs. For example, the synthesis of $\mathrm{Ag} / \mathrm{NPs}$ in solid form requires thermal decomposition method. With this technique, the complexation process between Ag and oleate was achieved for the preparation of Ag-NPs with small 10 $\mathrm{nm}$ size [69]. The synthesis of the monodisperse and uniform size of Ag/NPs by using a ceramic heating process [70]. Tien et al. reported a method to synthesize Ag/NPs was reported by using arc discharge technique. Ag/NPs were prepared synthetic by sputtering of metal into the reaction mixture, that is, physical deposition of $\mathrm{Ag}$ into glycerol. Physical techniques were utilized for the synthesis of $\mathrm{Ag} /$ NPs having uniform shape and size controlled by the thermal, power, and arc discharge. Safety should be considered when dealing with the nanoparticles $[71,72]$.

\section{Biological method}

Gold nanoparticles: In addition, a new method in green chemistry for the synthesis of Au/NPs has been recorded, in which Au/NPs were dissolved in $\mathrm{NaCl}$ solution from the bulk gold substrate by using natural chitosan without any stabilizer and reductant [73]. Another green synthesis method of $\mathrm{Au} / \mathrm{NPs}$ with size from $15-80 \mathrm{~nm}$ was reported. In this approach, $\mathrm{HAuCl}_{4}$ was used as a precursor and reduced by utilizing citrus fruit juice extracts (Citrus limon, Citrus reticulate and Citrus sinensis) [74]. The edible mushroom was also used for the preparation of $\mathrm{Au} / \mathrm{NPs}$ by light power [75].

Silver nanoparticles: Using classical methods for the synthesis of $\mathrm{Ag} / \mathrm{NPs}$ requires some parameters such as (a) reducing agent, (b) Ag precursors, and (c) stabilize agent (PVP) to prevent agglomeration of Ag/NPs). However, in biological or green methods, biomolecules replaced the traditional stabilizing and reducing agents. In the biological technique, Ag/NPs are prepared using green plants (such as algae, yeast, fungi, and bacteria) as stabilizing and reducing agents [76]. Shewanella one Dennis reducing agent (a metal reducing agent) was utilized for the biosynthesis of Ag/NPs. The reported Ag/NPs size was less than $15 \mathrm{~nm}$, with a spherical shape, and large surface area [77]. In another reported method, Trichoderma ride fungus was utilized for the green preparation of $\mathrm{Ag} / \mathrm{NPs}$ from $\mathrm{Ag}\left(\mathrm{NO}_{3}\right)$ as precursor [78]. The biopreparation of $\mathrm{Ag} / \mathrm{NPs}$ with size less than $50 \mathrm{~nm}$. However, the stability of $\mathrm{Ag} / \mathrm{NPs}$ with size $20 \mathrm{~nm}$ was obtained by using the bacteria (Bacillus sp.). The green-synthesized of Ag/NPs were collected from the periplasmic region (a space between outer and inner membrane) of the bacterial cell, and phyllanthin extract at room temperature [79]. Subbaiah reported that $\mathrm{Ag} / \mathrm{NPs}$ can also be prepared from Cadaba Fruticosa leaves by utilizing $\mathrm{Ag}\left(\mathrm{NO}_{3}\right)$ as a precursor. The biological preparation of nanoparticles was very powerful against microbes [80].

\section{Characterization of Silver and Gold Nanoparticles}

Characterization of nanoparticles is significant to evaluate the nature of nanoparticles. The characterization of nanoparticles can be performed by using transmission electron microscopy, scanning microscopy (TEM, SEM), UV-Vis spectroscopy, X-ray photoelectron spectroscopy (XPS), dynamic light scattering (DLS) atomic force microscopy (AFM), powder X-ray diffractometry (XRD), and Fourier transform infrared spectroscopy (FTIR) [81].

These techniques are used for determining various properties such as the size, geometry, shape, crystallinity, and surface area. For example, the morphology shape and particle size of nanoparticles could be specified by TEM, AFM, and SEM. Particle height and volume can be measured in three-dimensional images by AFM. Moreover, determination of particle size distribution can be by dynamic light scattering. Furthermore, the determination of crystallinity is performed by X-ray diffraction, while UV-Vis spectroscopy technique is used to confirm the formation by showing the plasmon resonance.

\section{Transmission electron spectroscopy (TEM)}

In the TEM technique, a few prepared NPs were put on the carboncoated copper grids. The micrographs of TEM for a drop of NPs are taken by utilizing the TEM instrument operated at an accelerating voltage of for example $200 \mathrm{kv} 9$. TEM grid is dry. A beam of photons is transmitted through an Ultra-thin specimen, and interacting with the specimen as it passes through. When the electrons transmitted through the specimen, an image is formed from the interaction. The magnification and focused on the image onto an imaging device [82]. 
TEM shows the size of gold nanoparticles with a different range from and illustrates the morphology image of gold nanoparticles, spherical shape, surface area, and the diameter can be indicated by this technique. TEM of silver nanoparticles can provide the morphology and the distribution of particle size for a profile of the Ag/NPs.

\section{Scanning electron microscope (SEM)}

This technique is used to study the size and morphology shape of the nanoparticles. A small sample was pipetted out and loaded on a stub provided for SEM analysis. The stub is made of copper, in the shape of a small cylinder about the size of $1 \mathrm{~mm}$ did one side of the stub was stuck with double sided carbon material. After putting the sample on the carbon material, the stub is fixed to a holder. The holder accommodates about 7 samples [83].

\section{Raman spectroscopy instrumentals}

The Raman technique has been explored using various materials such as gold, silver, and copper metals [84]. Raman enhancement on spheres of gold and silver with magnitude orders and have been confirmed in experiments [85]. The effect of gold and silver nanoparticle size in colloids [86] and core shells [87] on the surface plasmon resonance and SERS enhancement have also been recorded. It follows from the experiments and theoretical models [88] that the maximum SERS enhancements are seen when the surface plasmon resonance wavelength is equal to $\lambda \mathrm{sp}=(\lambda \mathrm{exc}+\lambda \mathrm{Rs}) / 2$, where $\lambda \mathrm{sp}, \lambda \mathrm{exc}$, and $\lambda \mathrm{Rs}$ are the surface plasmon, excitation, and Raman wavelength respectively. Furthermore, it was predicted that using different sizes of nanoparticles influences not only the surface plasmon wavelength but also the intensity of the electromagnetic field created in between the nanoparticles leading to higher SERS enhancements [89]. Differences between various metals were also investigated, revealing that the SERS enhancement of silver exceeds that of gold, which exceeds that of copper [90].

\section{UV-Vis spectroscopy}

The plasmon absorbance was responsible for characteristic colors of colloidal gold and silver nanoparticles. Conduction electrons on the surface of the nanoparticles and electromagnetic radiation are absorbed by incident light due to oscillations. The absorption maximum is adjusted in the range 0.5 and 0.7 ; the nanoparticle solution is diluted with distilled water. The plasmon resonance produces a peak near $400 \mathrm{~nm}$ with PWHM of 50 to $70 \mathrm{~nm}$. The wavelength of the plasmon absorption maximum in a given solvent can be used to indicate particle size. Silver nanoparticles that produce the spectrum are $(\lambda \max 400$ $\mathrm{nm}$ ) [91]. The absorbance spectra of gold nanoparticles are observed at $\sim 520 \mathrm{~nm}$ since the PA solution and the $\mathrm{HAuCl}_{4}$ do not have any absorbance at this wavelength.

\section{IR instruments}

Synthesized Ag/NPs were determined via utilizing Perkin Elmer Spectrum One FTIR with a spectral range between $4000-400 \mathrm{~cm}$ in solid $\mathrm{KBr}$ pellet. FTIR analysis was used for the characterization of the functional groups observed on the nanoparticles. The FTIR analysis of powder samples was prepared similarly as for powder diffraction calculations. The sample is placed in the two cells of $\mathrm{NaCl}$, after this the two cells contain the sample put in the holder of $\mathrm{KBr}$ pellet cells and eventually the detection occurs from the program on the computer to get the signal. The transmittance signal of gold nanoparticles is shown at 430.5 wavelengths and $\mathrm{OH}$ signals of the solution are shown at 3422.9 wavelengths (broad signal). The transmittance signal of silver nanoparticles is shown at $490 \mathrm{~nm}$ of the wavelength and $\mathrm{OH}$ signals wavelength of the solution is shown at $3422.9 \mathrm{~nm}$ (broad signal).

\section{XRD analysis}

$\mathrm{XRD}$ analysis is used to evaluate of a crystallite size of the aggregate nanoparticles. The measurements can be performed by using a Philips diffractometer of ' $\mathrm{X}$ ' pert company with nano chromatic $\mathrm{Cu} \mathrm{K} \otimes 1$ $(\lambda=1.54060 \AA)$ radiation. The size is determined by the width of XRD peaks using Scherrer's formula, $\mathrm{D}=0.86 \lambda / \beta \cos \theta$. The nanoparticles size and structure were obtained and confirmed by the XRD patterns of the products taken with a small amount of the sample. Furthermore, the three diffraction peaks were indicated by the XRD pattern in which agreed with (111), (200) and (220) diffractions of face-centered cubic silver. The metallic silver illustrates that high purity of fcc structure with all parameters $a=4.065$. Similarly, the XRD patterns of silver nanoparticles synthesized using $n$-butyl alcohol solvent shows a characteristic peak at $2 \theta=38.5$, marked with (111). It confirms the hypothesis of mono crystalline. The sharpening of peak clearly indicates that the particles are in the nano range. The particle size was also found and the value is higher than the ethylene glycol solvent. Hence, the particle size of silver nanoparticles is $9.99 \mathrm{~nm}$ and $42 \mathrm{~nm}$ for ethylene glycol and n-butyl alcohol respectively. The data are compared with the reported pure silver nitrate sample [92].

\section{Application of Gold and Silver Nanoparticles}

Figure 3 illustrates the various applications of nanoparticles in the pharmaceutical field. The wide applicability of the silver and gold nanoparticles is due to the novel properties of the nanoparticle, which help with applications excellent catalytic, good biocompatibility, large surface area, and conductivity. The bio sensing applications are widely used when the nanoparticles combined with biomolecules and used in combination of $\mathrm{Au} / \mathrm{NPs}$ and AuNPs/MPA (mercaptopropionic acid) used in the fabrication of biosensors which shows a wide linear range between $0.25 \mathrm{mM}$ and $1.25 \mathrm{mM}$ glucose concentration having detection limit of $0.025 \mathrm{mM}$ [93].

On the other hand, Ag/NPs have been widely used and known as an antimicrobial agent in the United States of America since 1954 [94]. Therefore, there is a more traditional approach to utilizing silver and gold by the ancient Egyptian and Romans. The oxidation state of $\mathrm{Ag}^{0}$ and $\mathrm{Ag}^{+1}$ are more stable compared with other oxidation states and can form different complexes.

\section{Application in biomedical}

Nanoparticles are used as biolabels in biomedical applications [95]. Immobilization and labeled of biomolecules on nanoparticles to give

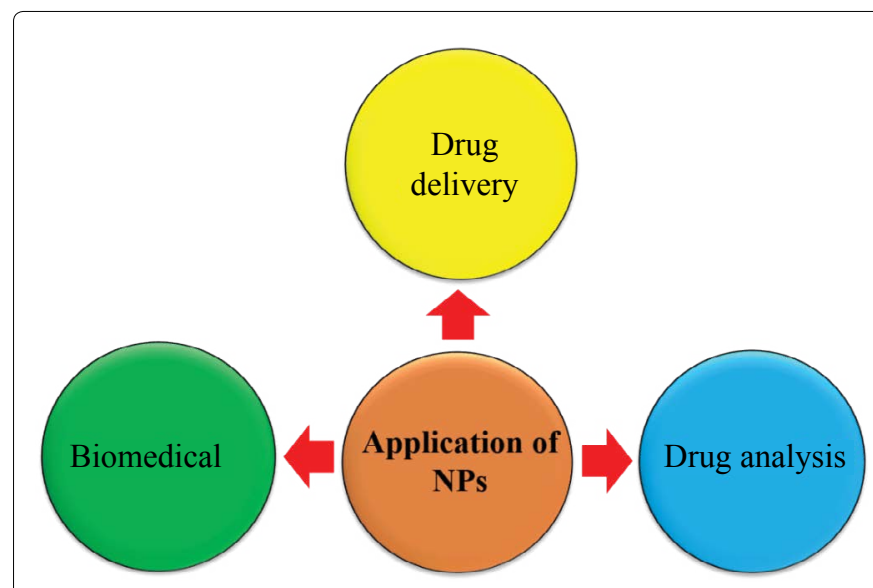

Figure 3: Application of gold and silver nanoparticles. 
hybrid molecules have been reported by different methods involved specific recognition, covalent coupling, physical adsorption, and electrostatic binding [96]. Gold nanoparticles are for example used in the gene therapy in vivo delivery, proteins, delivery of nucleic acids, and targeting [97]. Figure 4 illustrates the biomedical applications of the gold nanoparticles.

\section{Gold nanoparticle application in drug delivery}

The nanoparticles flow in endocytosis and are diffused through the lipid bilayer of the cell membrane. Nanoparticles conjugated with antibodies against exclusive cancer cell surface receptors are used to specifically bind with cancerous cells. The functionalized nanoparticles are used for targeted entry into cells. Phthalocyanine-stabilized gold nanoparticles have been shown to be a potential delivery vehicle for photodynamic therapy [98]. Functional nanoparticles of gold nanoparticles with a size of $20 \mathrm{~nm}$ were conjugated to different cellular targeting peptides to penetrate the biological membrane and target the nucleus. Different nanoparticles have also applied as targeted drugdelivery and biomarkers agents for diagnosis and medical treatment of cancer. Gold nanoparticles functionalized with targeted specific biomolecules can effectively destroy cancer cells or bacteria (Figure 5) [99]. Large surface to volume ratio of gold nanoparticles offers a large number of drug molecules being carried by the gold nanoparticles [100]. The functionalized nanoparticles used in drug delivery was demonstrated in Figure 6.

\section{Silver nanoparticle application in drug analysis}

Silver nanoparticles are commonly used due to their electrical conductivity, wide antimicrobial activity against various micro- organisms and localized surface plasmon resonance effect [101,102]. The $\mathrm{Ag} / \mathrm{NPs}$ have an important role in many applications such as surface-enhanced Raman scattering, catalyst, sensors, biomedical and antimicrobial applications. Insertion of $\mathrm{Ag} / \mathrm{NPs}$ onto supports is important for further exploration of Ag/NPs properties. For example, Wei et al. reported that the introduction of $\mathrm{Ag} / \mathrm{NPs}$ into GO sheets indicate that the antibacterial performance of $\mathrm{Ag} / \mathrm{GO}$ nanohybrids were enhanced compared with Ag-NPs alone. The Ag/GO hybrids show the non-toxic effect on rat skin [103]. Other reports [104] showed excellent antimicrobial activity for $\mathrm{Ag} / \mathrm{GO}$ nanohybrids. Figure 7 illustrates the synthesis of silver nanoparticles and used in drug analysis.

\section{Conclusion}

Gold and silver nanoparticles are prepared by various methods and used in different fields including drug delivery, sensing, and detection. The wide applicability is due to their extremely chemical and physical, high surface area, tunable optical, stability, properties small size, and non-cytotoxicity. Functionalized silver and gold nanoparticles with different biomolecules such as proteins, DNA, amino acids, and carboxylic acids have been used in cancer therapy and provide excellent drug delivery system. Targeted gold nanoparticles delivery interacts with the cancerous cell. Side effects of conventional drugs have been minimized by conjugation with gold nanoparticles. Ag/NPs have proven worthy in inhibiting the microbial proliferation and microbial infection. Furthermore, Ag/NPs have added a new dimension in the field of medicine concerning wound dressing and artificial implantation and in preventing contamination caused by microbes. Apart from that, $\mathrm{Ag} / \mathrm{NPs}$ play a pivotal role and are considered as important ingredients in the preparation of commercially used products in industries.

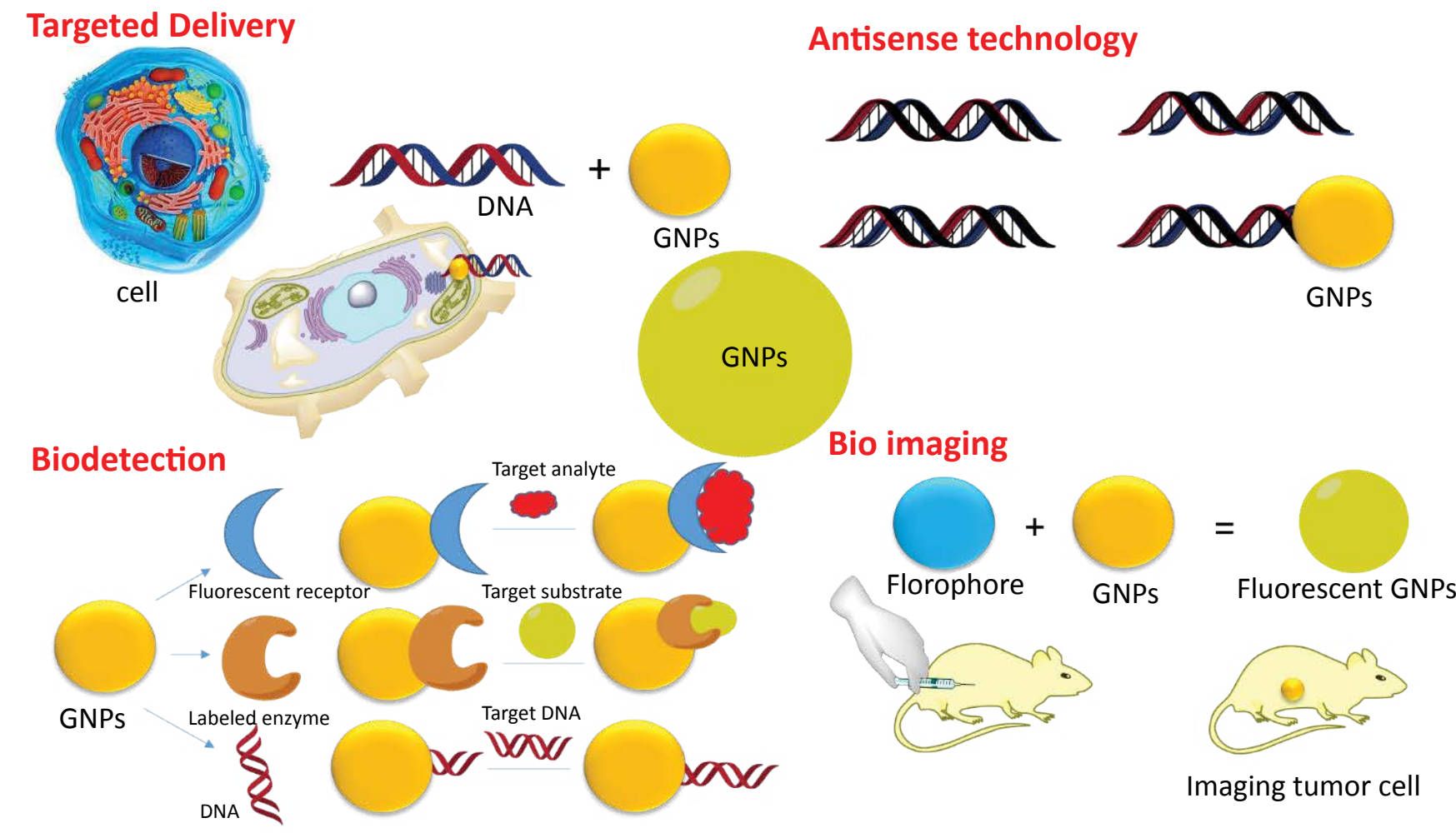

Figure 4: The potential application of Gold nanoparticles in the biomedical field. 
Citation: Alaqad K, Saleh TA (2016) Gold and Silver Nanoparticles: Synthesis Methods, Characterization Routes and Applications towards Drugs. J Environ Anal Toxicol 6: 384. doi:10.4172/2161-0525.1000384

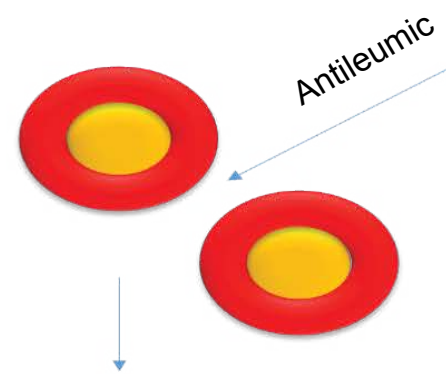

\section{GNPs}
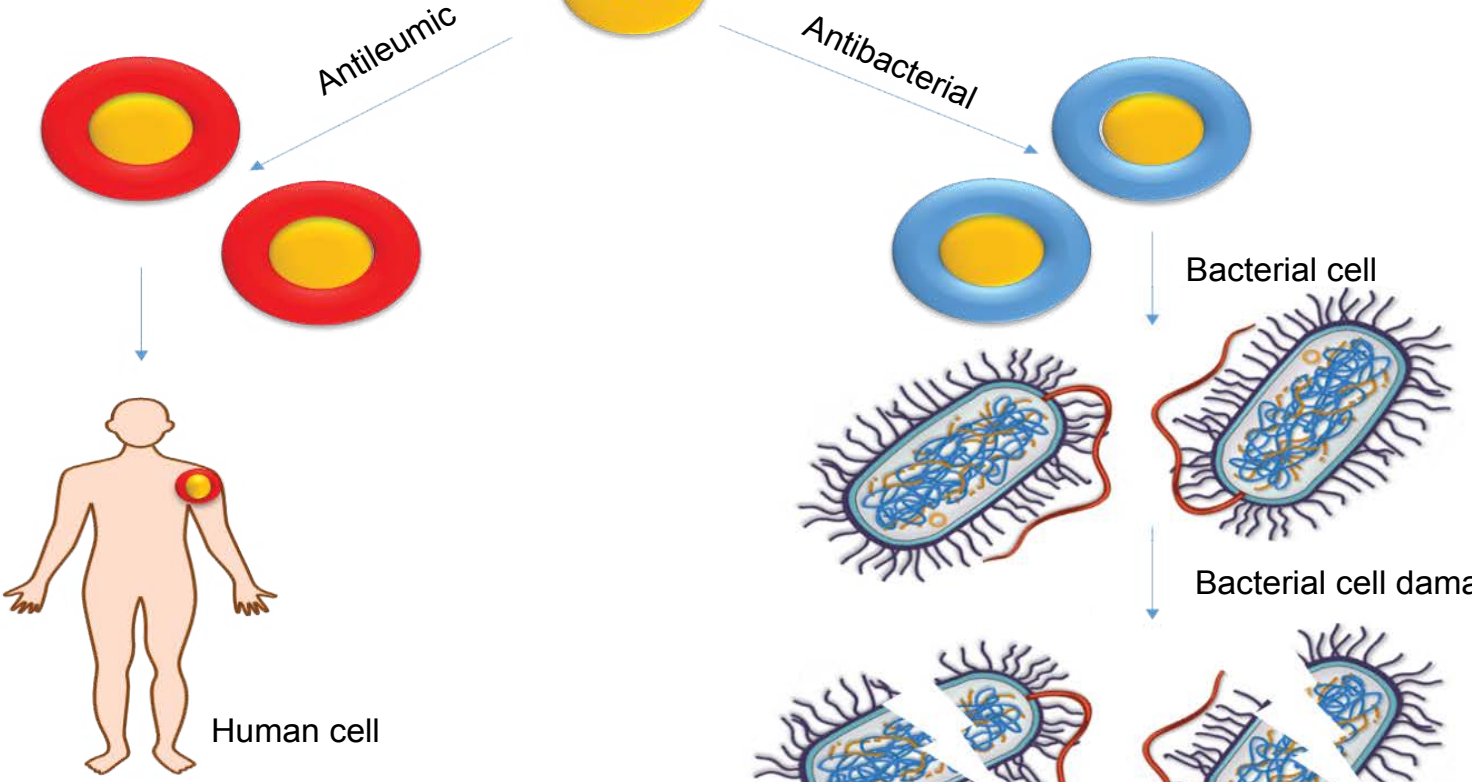

Bacterial cell damage

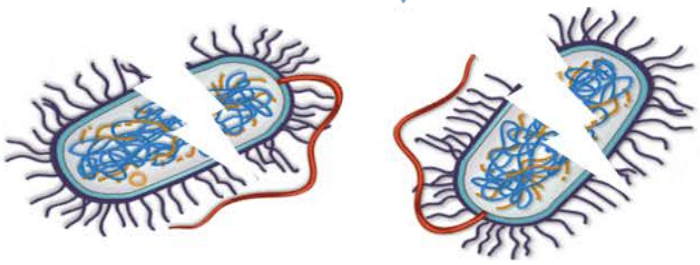

Figure 5: Functionalized GNP's (f-GNP) for drug delivery.

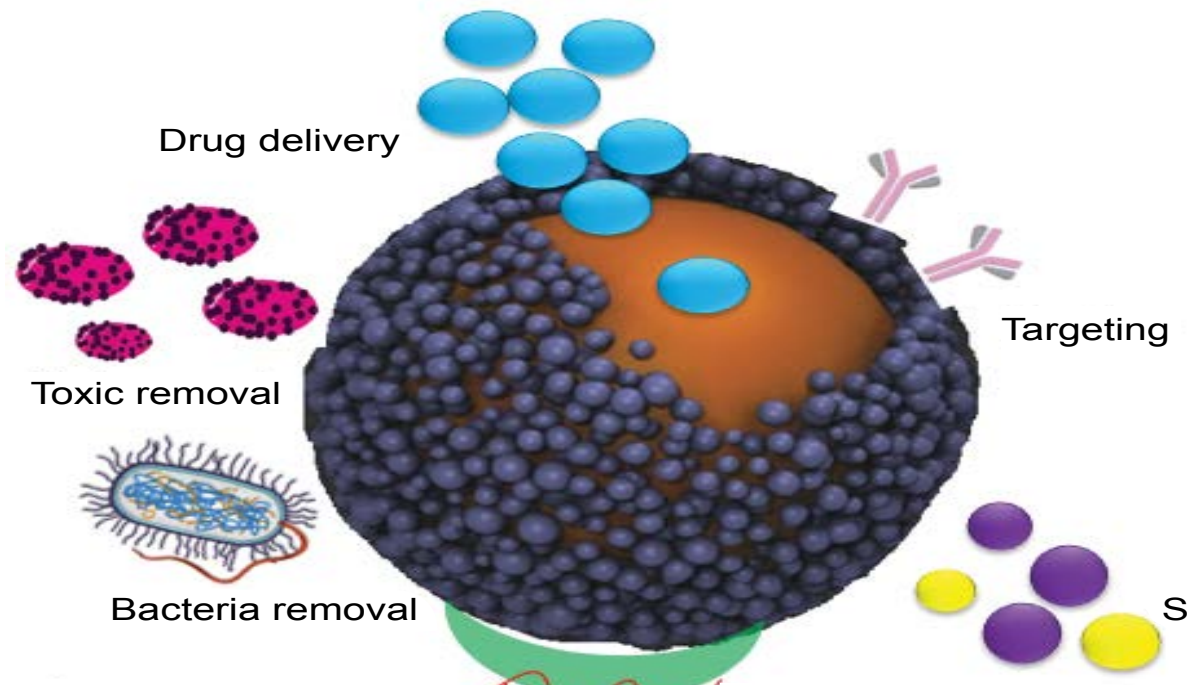

Separation

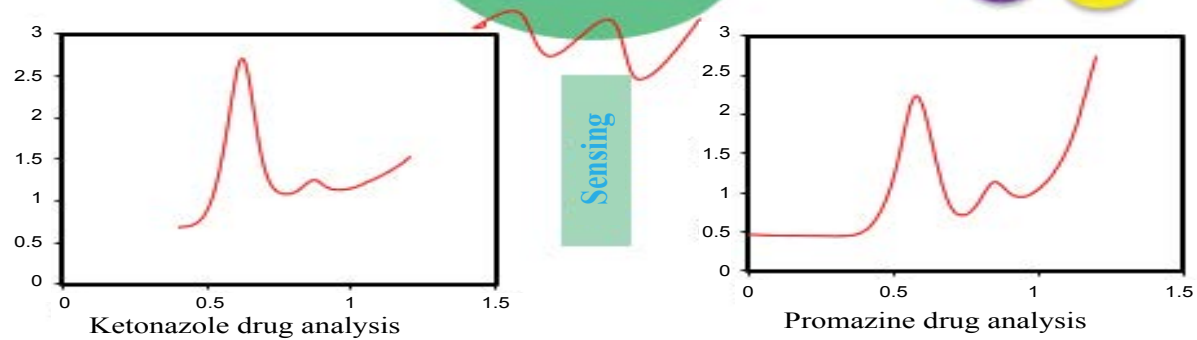

Figure 6: Applicability of gold nanoparticle in different fields including targeting, separation, drug delivery, sensing, and detection. 
Citation: Alaqad K, Saleh TA (2016) Gold and Silver Nanoparticles: Synthesis Methods, Characterization Routes and Applications towards Drugs. J Environ Anal Toxicol 6: 384. doi:10.4172/2161-0525.1000384

Page 8 of 10

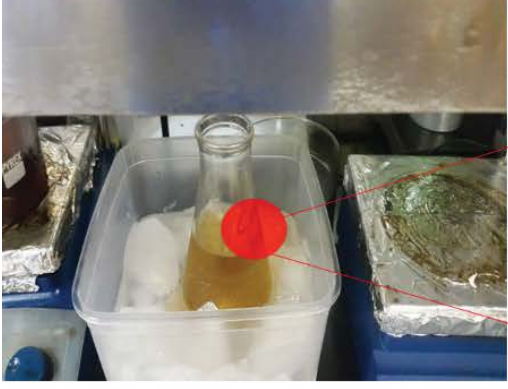

Synthesis silver nanoparticles

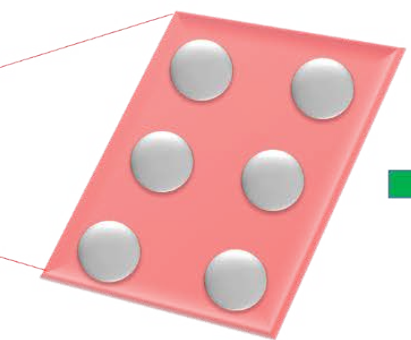

AgNPs

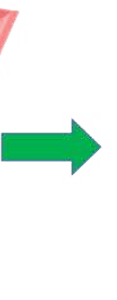

Drug capsules

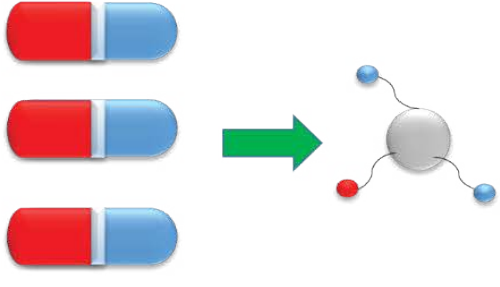

AgNPs carrier target drug

Figure 7: Applicability of silver nanoparticles in drug analysis.

\section{Acknowledgements}

The authors would like to acknowledge the Department of Chemistry, Faculty of Science at King Fahd University, Saudi Arabia.

\section{References}

1. Alanazi FK, Radwan AA, Alsarra IA (2010) Biopharmaceutical applications of nanogold. Saudi Pharm J 18: 179-193.

2. Di Guglielmo C, López DR, De Lapuente J, Mallafre JM, Suàrez MB (2010) Embryotoxicity of cobalt ferrite and gold nanoparticles: a first in vitro approach. Reprod Toxicol 30: 271-276.

3. Haruna K, Saleh TA, AIThagfi J, Al-Saadi AA (2016) Structural properties, vibrational spectra and surface-enhanced Raman scattering of 2, 4, 6-trichloroand tribromoanilines: A comparative study. Journal of Molecular Structure 1121: 7-15.

4. Saleh TA (2014) Detection: From Electrochemistry to Spectroscopy with Chromatographic Techniques, Recent Trends with Nanotechnology. Detection 2: $27-32$.

5. Tedesco S, Doyle H, Blasco J, Redmond G, Sheehan D (2010) Oxidative stress and toxicity of gold nanoparticles in Mytilus edulis. Aquat Toxicol 100: 178-186.

6. Mendoza KC, McLane VD, Kim S, Griffin JD (2010) Invitro application of gold nanoprobes in live neurons for phenotypical classification, connectivity assessment, and electrophysiological recording. Brain Res 1325: 19-27.

7. Hartono D, Hody, Yang KL, Yung LY (2010) The effect of cholesterol on protein-coated gold nanoparticle binding to liquid crystal-supported models of cell membranes. Biomaterials 31: 3008-3015.

8. Lukianova-Hleb EY, Wagner DS, Brenner MK, Lapotko DO (2012) Cell-specific transmembrane injection of molecular cargo with gold nanoparticle-generated transient plasmonic nanobubbles. Biomater 33: 5441-5450.

9. Mishra A, Tripathy SK, Yun SI (2012) Fungus mediated synthesis of gold nanoparticles and their conjugation with genomic DNA isolated from Escherichia coli and Staphylococcus aureus. Process Biochem 47: 701-711.

10. Etame AB, Smith CA, Chan WC, Rutka JT (2011) Design and potentia application of PEGylated gold nanoparticles with size-dependent permeation through brain microvasculature. Nanomed: Nanotechnol Biol Med 7: 992-1000.

11. Madu AN, Njoku PC, Iwuoha GN, Agbasi UM (2011) Synthesis and characterization of gold nanoparticles using 1-alkyl, 3-methyl imidazolium based ionic liquids International Journal of Physical Sciences 6: 635-640.

12. Garg N, Mohanty A, Lazarus N, Schultz L, Rozzi TR, et al. (2010) Robust gold nanoparticles stabilized by trithiols for application in chemiresistive sensors. Nanotechnology 21: 405501.

13. Alshalalfeh M, Sohail M, Saleh TA, Aziz M (2016) Electrochemical Investigation of Gold Nanoparticles-Modified Glassy Carbon Electrode and its Application for Ketoconazole Determination. Australian Journal of Chemistry.

14. Saleh TA (2014) Spectroscopy: Between Modeling, Simulation, and Practical Investigation. Spectral Analysis Review 2: 43252.
15. Chen PC, Mwakwari SC, Oyelere AK (2008) Gold nanoparticles: From nanomedicine to nanosensing. Nanotechnol Sci Appl 1: 45-65.

16. Sershen SR, Westcott SL, Halas NJ, West JL (2000) Temperature-sensitive polymer-nanoshell composites for photothermally modulated drug delivery. $J$ Biomed Mater Res 51: 293-298.

17. Vasir JK, Reddy MK, Labhasetwar VD (2005) Nanosystems in drug targeting opportunities and challenges. Current Nanoscience 1: 47-64.

18. Pissuwan D, Valenzuela SM, Cortie MB (2006) Therapeutic possibilities of plasmonically heated gold nanoparticles. Trends Biotechnol 24: 62-67.

19. Saleh TA (2011) Sensing of chlorpheniramine in pharmaceutical applications by sequential injector coupled with potentiometer. Journal of Pharmaceutical Analysis 1: 246-250

20. Idris AM, Ibrahim AEE, Abulkibash AM, Saleh TA, Ibrahim KEE (2011) Rapid inexpensive assay method for verapamil by spectrophotometric sequential injection analysis. Drug testing and analysis 3: 380-386.

21. Turkevich J, Garton G, Stevenson PC (1954) The color of colloidal gold. J Colloid Sci 9: (Suppl 1) 26-32.

22. Yu-Ying Y, Ser-Sing C, Chien-Liang L, Chris Wang CR (1997) Gold Nanorods: Electrochemical Synthesis and Optical Properties. J PhysChem B 101: 6661 6664.

23. Saleh TA, Gupta VK (2016) Nanomaterial and Polymer Membranes: Synthesis, Characterization, and Applications. 1st edn. Elsevier, ISBN-13: 9780128047033.

24. Murphy CJ, Sau TK, Gole AM, Orendorff CJ, Gao J, et al. (2005) Anisotropic metal nanoparticles: Synthesis, assembly, and optical applications. J Phys Chem B 109: 13857-13870.

25. Oldenburg SSJ, Averitt RD, Westcott SL, Halas NJ (1998) Nanoengineering of optical resonances. ChemPhysLett 288: 243-247.

26. Sun Y, Mayers BT, Xia Y (2002) Template-Engaged Replacement Reaction:? A One-Step Approach to the Large-Scale Synthesis of Metal Nanostructures with Hollow Interiors, Nano Lett 2: 481-485.

27. Stephan L, Mostafa AE (1999) Spectral Properties and Relaxation Dynamics of Surface Plasmon Electronic Oscillations in Gold and Silver Nanodots and Nanorods. J. PhysChem B 103: 8410-8426.

28. Frattini, N. Pellegri, D. Nicastro, de Sanctis O (2005) Effect of amine groups in the synthesis of Ag nanoparticles using aminosilanes Mater. Chem. Phys. 94 148-152.

29. Li P, Li J, Wu C, Wu Q, Li J (2005) Synergistic antibacterial effects of ß-lactam antibiotic combined with silver nanoparticles. J. Nanotechnol 16: 1912.

30. Alt V, Bechert T, Steinrücke P, Wagener M, Seidel $P$, et al. (2004) An in vitro assessment of the antibacterial properties and cytotoxicity of nanoparticulate silver bone cement. Biomaterials 25: 4383-4391.

31. Tran QH, Nguyen VQ, Anh-Tuan L (2013) Silver nanoparticles: synthesis, properties, toxicology, applications and perspectives. Adv. Nat. Sci. Nanosci. Nanotechnol 4: 033001. 
Citation: Alaqad K, Saleh TA (2016) Gold and Silver Nanoparticles: Synthesis Methods, Characterization Routes and Applications towards Drugs. J Environ Anal Toxicol 6: 384. doi:10.4172/2161-0525.1000384

32. Aymonier C, Schlotterbeck U, Antonietti L, Zacharias P, Thomann R (2002) Hybrids of silver nanoparticles with amphiphilic hyperbranched macromolecules exhibiting antimicrobial properties. Chem. Commun 24: 3018-3019.

33. Kumar A, Vemula PK, Ajayan PM, John G (2008) Silver-nanoparticle-embedded antimicrobial paints based on vegetable oil. Nat Mater 7: 236-241.

34. Lepape H, Solano-Serena F, Contini P, Devillers C, Maftah AP (2002) Evaluation of the anti-microbial properties of an activated carbon fibre supporting silver using a dynamic method Carbon 40: 2947-2954.

35. Yoon KY, Byeon JH, Park CW, Hwang J (2008) Antimicrobial effect of silver particles on bacterial contamination of activated carbon fibers. Environ Sci Technol 42: 1251-1255.

36. Bhattacharya R, Mukherjee P (2008) Biological properties of "naked" metal nanoparticles. Adv Drug Deliv Rev 60: 1289-1306.

37. Kamble VA, Jagdale DM, Kadam VJ (2010) Solid Lipid Nanoparticles as Drug Delivery System. International Journal of Pharma and Bio Sciences 1: 1-9.

38. Khan S (2012) Solid Lipid Nanoparticle: A Review. World Journal of Pharmacy and Pharmaceutical Sciences 1: 96-115

39. Deb S, Patra HK, Lahiri P, Dasgupta AK, Chakrabarti K, et al. (2011) Multistability in platelets and their response to gold nanoparticles. Nanomedicine 7: 376-384.

40. Ganeshkumar M, Sastry TP, Sathish Kumar M, Dinesh MG, Kannappan $S$, et al. Sun light mediated synthesis of gold nanoparticles as carrier for 6mercaptopurine: Preparation, characterization and toxicity studies in zebrafish

41. Guo Q, Guo Q, Yuan J, Zeng J (2014) Biosynthesis of gold nanoparticles using a kind of flavonol: Dihydromyricetin. Colloids and Surfaces A: Physicochemical and Engineering Aspects 441: 127-132.

42. Lan MY, Hsu YB, Hsu CH, Ho CY, Lin JC, et al. (2013) Induction of apoptosis by high-dose gold nanoparticles in nasopharyngeal carcinoma cells. Auris Nasus Larynx 40: 563-568.

43. Giljohann DA, Seferos DS, Daniel WL, Massich MD, Patel PC, et al. (2010) Gold nanoparticles for biology and medicine. Angew Chem Int Ed Engl 49: 3280-3294.

44. Amjadi M, Farzampour $L$ (2014) Fluorescence quenching of fluoroquinolones by gold nanoparticles with different sizes and its analytical application. J Luminesc 145: 263-268.

45. Murawala P, Tirmale A, Shiras A, Prasad BL (2014) In situ synthesized BSA capped gold nanoparticles: effective carrier of anticancer drug methotrexate to MCF-7 breast cancer cells. Mater Sci Eng C Mater Biol Appl 34: 158-167.

46. Lu AH, Salabas EL, Schuth F (2007) Magnetic nanoparticles: synthesis, protection, functionalization, and application. Angewandte Chemie 46: 1222-1244

47. Sharma VK, Yngard RA, Lin Y (2009) Silver nanoparticles: green synthesis and their antimicrobial activities. Advances in Colloid and Interface Science 145: 83-96.

48. Krutyakov YA, Kudrinskiy AA, Olenin AY, Lisichkin GV (2008) Synthesis and properties of silver nanoparticles: advances and prospects. Russian Chemical Reviews 77: 233-257.

49. Monteiro DR, Gorup LF, Takamiya AS, Ruvollo-Filho AC, Camargo ERD, et al (2009) The growing importance of materials that prevent microbial adhesion: antimicrobial effect ofmedical devices containing silver. International Journal of Antimicrobial Agents 34: 103-110.

50. Ahamed M, Alsalhi MS, Siddiqui MK (2010) Silver nanoparticle applications and human health. Clin Chim Acta 411: 1841-1848.

51. Fabrega J, Luoma SN, Tyler CR, Galloway TS, Lead JR (2011) Silver nanoparticles: behaviour and effects in the aquatic environment. Environment International 37: 517-531.

52. Papasani MR, Wang G, Hill RA (2012) Gold nanoparticles: the importance of physiological principles to devise strategies for targeted drug delivery. Nanomedicine 8: 804-814.

53. Sun X, Zhang G, Keynton RS, O'Toole MG, Patel D, Gobin AM (2013) Enhanced drug delivery via hyperthermal membrane disruption using targeted gold nanoparticles with PEGylated Protein-G as a cofactor. Nanomed: Nanotechnol Biol Med 9: 1214-1222.

54. Saleh TA (2011) The influence of treatment temperature on the acidity of MWCNT oxidized by $\mathrm{HNO}_{3}$ or a mixture of $\mathrm{HNO}_{3} / \mathrm{H}_{2} \mathrm{SO}_{4}$, Applied surface science 257: 7746-7751.
55. Saleh TA (2013) The role of carbon nanotubes in enhancement of photocatalysis. Syntheses And Applications Of Carbon Nanotubes And Their Composites 479-493.

56. Saleh TA, Abulkibash AM, Ibrahim AE (2012) Portable system of programmable syringe pump with potentiometer for determination of promethazine in pharmaceutical applications. Saudi Pharmaceutical Journal 20: 155-160.

57. Heidari Z, Sariri R, Salouti M (2014) Gold nanorods-bombesin conjugate as a potential targeted imaging agent for detection of breast cancer. J Photochem Photobiol B 130: 40-46.

58. Bisker G, Yeheskely-Hayon D, Minai L, Yelin D (2012) Controlled release of Rituximab from gold nanoparticles for phototherapy of malignant cells. J Control Release 162: 303-309.

59. Yu J, Zhou X (2013) Synthesis of dendritic silver nanoparticles and their applications as SERS substrates. Advances inMaterials Science and Engineering ID 519294.

60. Sun Y, Xia Y (2002) Shape-controlled synthesis of gold and silver nanoparticles. Science 298: 2176-2179.

61. Saleh TA, Gupta VK (2014) Covalent and Non-Covalent Functionalization of Carbon Nanotubes. Advanced Carbon Materials and Technology.

62. Chen M, Feng YG, Wang X, Li TC, Zhang JY, et al. (2007) Silver nanoparticles capped by oleylamine: formation, growth, and self-organization. Langmuir 23 : 5296-5304.

63. Mukherji S, Agnihotri S (2014) Size-controlled silver nanoparticles synthesized over the range $5-100 \mathrm{~nm}$ using the same protocol and their antibacterial efficacy. RSC Advances 4: 3974-3983.

64. Evanoff DD, Chumanov G (2004) Size-controlled synthesis of nanoparticles. 2 Measurement of extinction, scattering, and absorption cross sections. J Phys Chem B 108: 13957-13962.

65. Rezende TS, Andrade GRS, Barreto LS, Costa Jr NB, Gimenez IF, Almeida LE (2010) Facile preparation of catalytically active gold nanoparticles ona thiolated chitosan. Mater Lett 64: 882-884.

66. Guo W, Pi Y, Song H, Tang W, Sun J (2012) Layer-by-layer assembled gold nanoparticles modified anode and its application in microbial fuel cells. Colloid Surfac A: Physicochem Engineer Aspects 415: 105-111.

67. Chen K-S, Hung T-S, Wu H-M, Wu J-Y, Lin M-T, Feng CK (2010) Preparation of thermosensitive gold nanoparticles by plasma pretreatment and UV grafted polymerization. Thin Solid Films 518: 7557-7562.

68. Kojima C, Umeda Y, Harada A, Kono K (2010) Preparation of near-infrared ligh absorbing gold nanoparticles using polyethylene glycol-attached dendrimers. Colloid Surfac B, Biointerfac 81: 648-651.

69. Lee DK, Kang YS (2004) Synthesis of silver nanocrystallites by a new therma decomposition method and their characterization. ETRI Journal 26: 252-256.

70. Jung JH, Cheol Oh H, Soo Noh H, Ji JH, Soo Kim S (2006) Metal nanoparticle generation using a small ceramic heater with a local heating area. Journal of Aerosol Science 37: 1662-1670.

71. TA Saleh (2011) Testing the effectiveness of visual aids in chemical safety training. Journal of Chemical Health and Safety 18: 3-8.

72. TA Saleh (2013) A strategy for integrating basic concepts of nanotechnology to enhance undergraduate nano-education: Statistical evaluation of an application study. Journal of Nano Education 4: 1-7.

73. Namazi H, Fard AMP (2011) Preparation of gold nanoparticles in the presence of citric acid-based dendrimers containing periphery hydroxyl groups. Mate Chem Physic 129: 189-194.

74. Tarnawski R, Ulbricht M (2011) Amphiphilic gold nanoparticles: Synthesis, characterization and adsorption to PEGylated polymer surfaces. Colloid Surfac A: Physicochem Engineer Aspects 374: 13-21.

75. Nalawade P, Mukherjee T, Kapoor S (2012) High-yield synthesis of multispiked gold nanoparticles: Characterization and catalytic reactions. Colloid Surfac A Physicochem Engineer Aspects 396: 336-340.

76. Sintubin L, Verstraete W, Boon N (2012) Biologically produced nanosilver: current state and future perspectives. Biotechnol Bioeng 109: 2422-2436.

77. Suresh K, Pelletier DA, Wang W (2010) Silver nanocrystallites: biofabrication using shewanella oneidensis, and an evaluation of their comparative toxicity on gram-negative and gram-positive bacteria. Environmental Science and Technology 44: 5210-5215. 
Citation: Alaqad K, Saleh TA (2016) Gold and Silver Nanoparticles: Synthesis Methods, Characterization Routes and Applications towards Drugs. J Environ Anal Toxicol 6: 384. doi:10.4172/2161-0525.1000384

78. Fayaz M, Balaji K, Girilal M, Yadav R, Kalaichelvan PT, et al. (2010) Biogenic synthesis of silver nanoparticles and their synergistic effect with antibiotics: a study against gram-positive and gram-negative bacteria. Nanomedicine: Nanotechnology, Biology, andMedicine 6: 103-109.

79. Thirumalai Arasu V, Prabhu D, Soniya M (2010) Stable silver nanoparticle synthesizing methods and its applications. Journal of Biosciences Research 1: $259-270$.

80. Venkata Subbaiah KP, Savithramma N (2013) Synthesis of silver nanoparticles and antimicrobial activity from Cadaba fruticosa-an important ethnomedicinal plant to treat Vitiligo of kurnool district, andhra Pradesh. Indo American Journal of Pharmaceutical Research 3: 1285-1292.

81. Choi $\mathrm{Y}$, Ho NH, Tung $\mathrm{CH}$ (2007) Sensing phosphatase activity by using gold nanoparticles. Angew Chem Int Ed Engl 46: 707-709.

82. Krishnamoorthy P, Jayalakshmi T (2012) Preparation, characterization and synthesis of silver nanoparticles by using phyllanthusniruri for the antimicrobial activity and cytotoxic effects. Journal of Chemical and Pharmaceutical Research 4: 4783-4794.

83. Shanmuga Priya T, Balasubramanian V (2014) Enzyme Mediated Synthesis of Silver Nanoparticles using Marine Actinomycetes and Their Characterization. Biosciences Biotechnology Research Asia. 11: 159-165.

84. Wang T, Hu X, Dong S (2006) Surfactantless synthesis of multiple shapes of gold nanostructures and their shape-dependent SERS spectroscopy. J Phys Chem B 110: 16930-16936.

85. Barber PW, Chang RK, Massoudi H (1983) Electrodynamic calculations of the surface-enhanced electric intensities on large Ag spheroids. Physical Review B 27: 7251-7261.

86. Rivas L, Sanchez-Cortes S, Garcia-Ramos JV, Morcillo G (2000) Mixed silver/ gold colloids: a study of their formation, morphology, and surface-enhanced Raman activity. Langmuir 16: 9722-9728.

87. Mandal M, Jana NR, Kundu S, Ghosh SK, Panigrahi M, et al. (2004) Synthesis of Aucore-Agshell type bimetallic nanoparticles for single molecule detection in solution by SERS method. Journal of Nanoparticle Research 6: 53-61.

88. Felidj N, Aubard J, evi GL (2002) Controlling the optical response of regular arrays of gold particles for surfaceenhanced Raman scattering. Physical Review B 65: ID 075419

89. Li K, Li X, Stockman MI, Bergman DJ (2005) Surface plasmon amplification by stimulated emission in nanolenses. Physical Review B 71: ID 115409.

90. Kneipp K, Moskovits M, Kneipp H (2006) Surface-Enhanced Raman Scattering: Physics and Applications. Springer, Berlin, Germany.
91. Solomon SD, Bahadory M, Jeyarajasingam AV, Rutkowsky SA, Boritz C (2007) Synthesis and Study of Silver Nanoparticles. Journal of Chemical Education 84: 322.

92. Alagumuthu G, Kirubha R (2012) Synthesis and Characterisation of Silver Nanoparticles in Different Medium. Open Journal of Synthesis Theory and Applications 1: 13-17.

93. Rastogi L, Kora AJ (2012) Highly stable, protein capped gold nanoparticles as effective drug delivery vehicles for amino-glycosidic antibiotics. Mater Sci Engineer: 32: 1571-1577.

94. Nowack B, Krug HF, Height M (2011) 120 years of nanosilver history: implications for policy makers. Environmental Science and Technology 45 1177-1183.

95. Wang G, Stender AS, Sun W, Fang N (2010) Optical imaging of non-fluorescent nanoparticle probes in live cells. Analyst 135: 215-221.

96. Daraee H, Eatemadi A, Abbasi E, Fekri Aval S, et al. (2016) Application of gold nanoparticles in biomedical and drug delivery. Artif Cells Nanomed Biotechnol 44: 410-422.

97. Raghavendra R, Arunachalam K, Annamalai SK, Arunachalam AM (2014) Diagnostics and Therapeutic Application Of Gold Nanoparticles 6: suppl 2.

98. Doubrovsky VA, Yanina IY, Tuchin VV (2010) Inhomogeneity of photo-induced fat cell lipolysis. In: Tuchin VV, Genina EA (eds.), Sartov Fall Meeting. United Kingdom. International Society for Optics and Photonics.

99. Duncan B, Kim C, Rotello VM (2010) Gold nanoparticle platforms as drug and biomacromolecule delivery systems. J Control Release 148: 122-127.

100. Grace NA, Pandian K (2007) Antibacterial efficacy of aminoglycosidic antibiotics protected gold nanoparticles-A brief study. Colloids Surf. A 297: 63-70.

101. Chernousova S, Epple M (2013) Silver as antibacterial agent: ion, nanoparticle, and metal. Angew Chem Int Ed Engl 52: 1636-1653.

102. Shen J, Shi M, Li N, Yan B, Ma Ho, et al. (2010) Facile synthesis and application of Ag-chemically converted graphene nanocomposite. Nano Res 3: 339-349.

103. Wei-Ping X, Le-Cheng Z, Jian-Ping L, Yang L, Hui-Hui L, et al. (2011) Facile synthesis of silver@graphene oxide nanocomposites and their enhanced antibacterial properties. J. Mater. Chem 2: 4593-4597.

104. Das MR, Sarma RK, Borah SC, Kumari R, Saikia R, et al. (2013) The synthesis of citrate-modified silver nanoparticles in an aqueous suspension of graphene oxide nanosheets and their antibacterial activity. Colloids Surf B 105: 128-136. 